\title{
Apoptotic mimicry as a strategy for the establishment of parasitic infections: parasite- and host-derived phosphatidylserine as key molecule
}

\author{
João Luiz Mendes Wanderley ${ }^{1 *}$, Renato Augusto DaMatta ${ }^{2}$ and Marcello André Barcinski ${ }^{3}$
}

\begin{abstract}
The establishment of parasitic infection is dependent on the development of efficient strategies to evade the host defense mechanisms. Phosphatidylserine (PS) molecules are pivotal for apoptotic cell recognition and clearance by professional phagocytes. Moreover, PS receptors are able to trigger anti-inflammatory and immunosuppressive responses by phagocytes, either by coupled enzymes or through the induction of regulatory cytokine secretion. These PS-dependent events are exploited by parasites in a mechanism called apoptotic mimicry. Generally, apoptotic mimicry refers to the effects of PS recognition for the initiation and maintenance of pathogenic infections. However, in this context, PS molecules can be recognized on the surface of the infectious agent or in the surface of apoptotic host debris, leading to the respective denomination of classical and non-classical apoptotic mimicry. In this review, we discuss the role of PS in the pathogenesis of several human infections caused by protozoan parasites.
\end{abstract}

Keywords: Phosphatidylserine, Apoptotic mimicry, Parasites, Host-parasite interplay

\section{Background}

\section{Apoptosis and apoptotic mimicry}

Parasites have to cope with the host immune system to establish infection. These organisms acquire evolutive adaptations to evade, inhibit or deviate the immune response, aiming to turn the host permissive to infection maintenance and dissemination. In several systems, parasites make use of host molecules to achieve this goal or display their own immune-modulating molecules. The observation of apoptotic death or apoptotic-like phenotypes in parasites raised several questions regarding the consequences of such mechanism operating in unicellular parasitic organisms [1-4]. Currently, it is well established that apoptotic cells or apoptotic-derived molecules play a role in the establishment and the outcome of different parasitic infections. This mechanism was first demonstrated in 2001, when it was observed that amastigote forms of Leishmania amazonensis are

\footnotetext{
* Correspondence: Imwjoao@macae.ufrj.br

${ }^{1}$ Laboratório de Imunoparasitologia, Campus UFRJ Macaé, Universidade

Federal do Rio de Janeiro, Rio de Janeiro, RJ, Brazil

Full list of author information is available at the end of the article
}

able to expose phosphatidylserine (PS) in the outer leaflet of the plasma membrane, and that this molecule is important for amastigote infection and maintenance of the consequent experimental leishmanial disease [5]. PS is one of the main early-stage apoptotic molecules displayed by dying cells [6]. PS exposure occurs due to a caspase-dependent plasma membrane asymmetry loss, caused by the cleavage of phospholipid translocases [7, 8]. Once in the cell surface, PS recognition by epithelial and immune cells triggers the endocytosis of the target cell, as well as the activation of anti-inflammatory and immunosuppressive responses by the phagocyte $[9,10]$.

The effects of PS recognition in the regulation of local and systemic inflammation and the promotion of immune tolerance are advantageous for parasite establishment and dissemination, independently on the source of PS. Following the demonstration of apoptotic mimicry in an experimental model of infection by L. amazonensis, several papers reported that different versions of the apoptotic mimicry operate in assorted models, such as in other parasite and viral infections and in tumor development [11-13]. In all these cases, PS recognition is 
involved in the pathogenesis and maintenance of the disease caused by those infective agents and tumor cells. The better understanding of the role of PS in these events led to the description of two distinct patterns of apoptotic mimicry: classical and non-classical apoptotic mimicry [12]. Classical apoptotic mimicry ensues when the source of PS is the plasma membrane of the organism or cell taking advantage of PS recognition. This mechanism operates in (a): enveloped viral infections. Several viruses are able to invade and deactivate host cells through PS on their envelope surface [11, 12, 1416], (b): tumor development. Tumor cells and shed microvesicles display PS on their surface, promoting tumor spreading, immune tolerance and endothelial cell activation [11, 13, 17-19], and (c) parasite infections, which are the focus of the present review. On the other hand, non-classical apoptotic mimicry occurs when pathogens or tumor cells take advantage of PS exposed by host cells, either by inducing cell death in host cells, or following natural death due to host cell activation or inflammation. This is the case of some non-enveloped viruses [12] and parasites.

In this review we propose to discuss the role of PS in the context of both classical and non-classical apoptotic mimicry, on the perspective of different parasite infections of interest for human health.

\section{Classical apoptotic mimicry \\ Definition}

Apoptotic mimicry was first demonstrated as a strategy employed by intracellular parasites in which exposed PS acts as a signal for parasite internalization in host cells and induces an anti-inflammatory response. PS translocation to the outer leaflet of the plasma membrane can occur transiently in several circumstances, such as $\mathrm{T}$ cell, mast cell and platelet activation, myotube formation and endothelial cell inflammatory stimulation [20-25]. However, constitutive and irreversible PS translocation is a characteristic of early apoptotic cells and is usually followed by cell death $[6,7,26,27]$. In the original description of apoptotic mimicry, viable L. amazonensis amastigotes were shown to expose PS as a strategy to persist in the host [5]. The main impact of this mechanism was the decrease in nitric oxide (NO) production by infected macrophages. NO is the main macrophagic microbicidal molecule with activity against parasites, since it is capable of inactivate several metabolic enzymes by nitrosylation reactions [28]. Currently, in addition to the original description, it is well established that PS exposed on viral particles, tumor cells and, particularly, protozoan parasites can play a similar role [11]. Thus, in the first part of this review we will discuss the role of PS molecules in classical apoptotic mimicry performed by parasites of importance in human diseases.

\section{Leishmania amazonensis}

Parasites of the genus Leishmania are the causative agents of leishmaniasis, a neglected disease that affects 1,3 million people, mostly in tropical and subtropical countries, leading to 20.000 deaths per year. It is estimated that over 1 billion people live in endemic areas at risk of infection [29]. These protozoan organisms are heteroxenic parasites that infect phlebotomine sandfly vectors and mammalian hosts, including humans. Promastigote forms survive in the intestinal tract of phlebotomines and differentiate into metacyclic promastigotes, the infective stage for mammalian hosts. When deposited in the lesion during blood feeding, metacyclics are able to resist the innate immune system and infect phagocytic cells, differentiating into non-motile, rounded amastigotes. These forms are able to proliferate inside parasitophorous vacuoles in the host cell, adding to cell disruption, infection of new host cells and dissemination [30, 31].

The observation of PS exposure in L. amazonensis parasites was made when promastigote forms were submitted to a heat shock by transferring them from $23^{\circ} \mathrm{C}$ to $37^{\circ} \mathrm{C}$, mimicking the temperature shift during a natural infection. Most promastigotes under these stressful conditions lose their viability, normal morphology and energetic metabolism [32]. Amastigote forms are adapted to the higher temperatures and lower $\mathrm{pH}$ encountered in mammalian hosts; therefore, they should not display apoptotic features in these conditions [33, 34]. However, when purified from mice lesions or macrophages in in vitro cultures, amastigotes expose PS in the outer leaflet of the plasma membrane, despite the maintenance of viability, morphology, and ability to infect other cells, animals, phlebotomine sandflies and to differentiate into promastigote forms [5, 35-37]. This observation led to the question whether PS exposure on amastigotes plays a role in the normal biology of the parasite, unrelated to cell death. It was observed that the recognition of PS on the surface of these parasites is fundamental for amastigote uptake by macrophages and, most importantly, to induce a permissive status in the host cell, allowing parasite intracellular growth and maintenance [5, 35-37]. During amastigote infection, PS is able to induce TGF$\beta 1$ and IL-10 production by macrophages, which decreases NO production $[5,35,36]$. Actually, the events triggered by PS recognition on amastigotes are similar to the ones observed during apoptotic cell recognition, as depicted in Fig. 1a. This similarity inspired the apoptotic mimicry concept to describe the phenomenon [5].

It is well established that susceptibility and resistance to Leishmania infection depends on the genetic background of the host, which, in turn, defines the properties of the anti-parasite immune response [31]. The first observation of apoptotic mimicry in amastigotes was made in the $\mathrm{BALB} / \mathrm{c}$ mouse model of infection. $\mathrm{BALB} / \mathrm{c}$ mice 


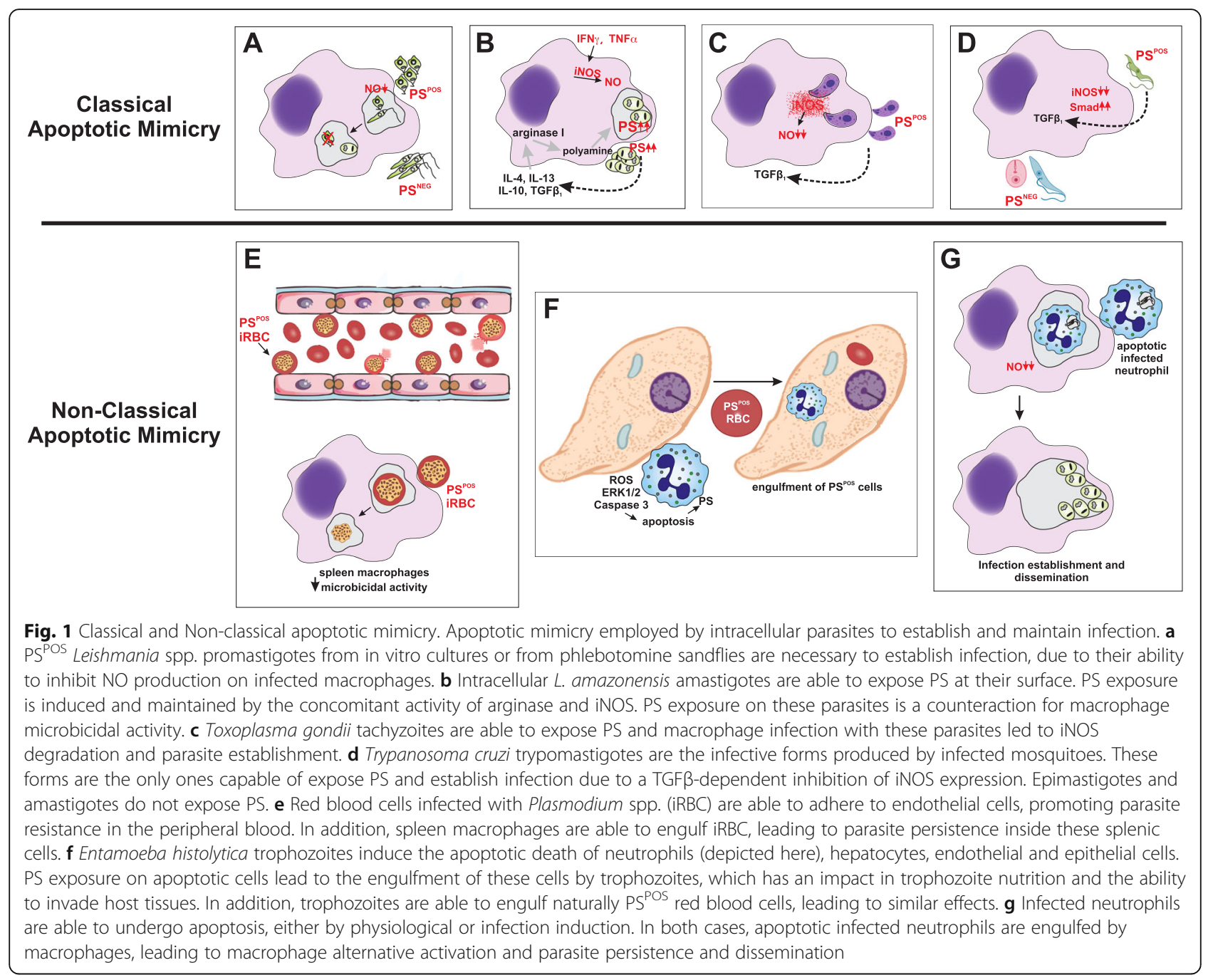

are susceptible to the infection with most of Leishmania species [31, 38]. In L. amazonensis infection, when amastigotes are obtained from mice strains with different susceptibility profiles, it was observed that PS exposure also varies, and directly correlates with host susceptibility [35], indicating that PS exposure on the amastigote is regulated by host intrinsic factors. Amastigotes purified from different mice strains and, therefore, with different amounts of PS exposed, maintain their distinctive infection capacity when infecting an unrelated host confirming that the amount of PS exposed defines the infective capacity of these parasites [35]. Interestingly, it was observed that an intrinsic pressure from the immune system is responsible to induce PS exposure on intracellular amastigotes. Amastigotes obtained from infected immune-deficient mice do not expose PS at their surface and the adoptive transfer of immune-competent primed $\mathrm{T}$ lymphocytes revert this phenotype [36]. Experimental evidences suggest that NO synthesis pathway is responsible for the induction of PS exposure on intracellular amastigotes, since the immune activation of infected iNOS (inducible nitric oxide synthase) KO macrophages does not stimulate PS exposure on the intracellular parasites. In addition, PS-dependent induction of polyamine synthesis by infected macrophages protects PS-exposing amastigotes from death. Infected macrophages that induce PS exposure on the intracellular parasites must maintain detectable levels of iNOS and arginase 1 expression [36]. Therefore, PS exposure is an adaptive response of intracellular amastigotes of $L$. amazonensis that counteracts the immune activation of the host cell. The biochemical mechanisms that regulate the translocation of PS in the parasite need to be determined, although there are some reports indicating that PS exposure in Leishmania parasites may be independent on metacaspase activation, dependent on endoplasmic reticulum oxidative stress in some species or dependent on caspase-like activity [39-42]. In addition, it is necessary to elucidate whether PS exposure on amastigotes occurs in different Leishmania species and its role for the establishment of the infection. 
As already stated, PS-exposing promastigotes are undergoing apoptotic death and, therefore, are not viable [43-45]. However, PS-exposing promastigotes do cooperate with viable parasites to establish infection (Fig. $1 b)$. The population of infective promastigotes derived from in vitro cultures and from phlebotomine sandflies contains a significant percentage of apoptotic, nonviable, PS-exposing parasites [44, 45]. The removal of the non-viable, PS-exposing parasites from the infective inoculum, decreases and, depending on the efficiency of the purification method, can even abrogate its infective capacity [44, 45]. The lack of nutrients in the culture media or in the intestinal tract of the sandfly is one of the signals that drive the differentiation of metacyclic promastigotes [46]. It is possible that a sub-population of promastigotas, unable to cope with these conditions, dies by apoptosis exposing PS in the process. Apoptotic metacyclic promastigotes are able to modulate macrophage activation allowing the establishment of the viable parasites. This mechanism was shown to operate in different Leishmania species, such as L. major, the main species related to leishmaniasis in the Mediterranean Europe, western Asia and north Africa and L. amazonensis, the causative agent of diffuse and disseminated leishmaniasis in the America [44, 45].

\section{Trypanosoma cruzi}

Chagas disease affects about 8 million people in the world [47] and is caused by the protozoan Trypanosoma cruzi that exists in three basic forms: amastigotes, trypomastigotes and epimastigotes. Trypomastigotes are released in the invertebrate vector feces and gain access to the mammalian host at the site of the vector bite or through a mucosal entry, infect host cells and differentiate into amastigotes that multiply and differentiate back into trypomastigotes. These forms are eventually drawn by the blood sucking vectors and in their gut differentiate into epimastigotes that turn back into trypomastigotes in the rectum of the vector [47].

All three forms have been studied to better understand the biology of the parasite. Epimastigotes are replicative forms that are killed by vertebrate host cells. Amastigotes are replicative intracellular forms, found in the vertebrate host cells that are capable of new infections and trypomastigotes are infective forms unable to replicate and when released by the vector, needs to cope with the vertebrate immune system [48]. PS exposure has been analyzed in all three forms of the parasite [49]. About $50 \%$ of trypomastigotes from mice blood or obtained from Vero cultures are able to expose PS at the outer leaflet of their plasma membrane. Epimastigotes and amastigotes do not to expose PS. When trypomastigotes differentiate into epimastigotes, PS exposure is abolished. In addition, trypomastigotes are able to trigger a TGF- $\beta 1$ signaling pathway, leading to a decreased expression of iNOS in infected activated mice macrophages [49], as described in Fig. 1c. Thus, only the form that interacts with host macrophages, during the establishment of the infection, exposes PS.

\section{Toxoplasma gondii}

Toxoplasma gondii is an obligatory intracellular parasite of the phylum apicomplexan and is the etiological agent of toxoplasmosis. In humans, toxoplasmosis is one of the most recurrent infections infecting around 1/3 of the world's population [50]. T. gondii was the second described protozoan capable of employ classical apoptotic mimicry [51]. Exposure of PS to the outer surface of $T$. gondii plasma membrane induces macrophage to release TGF- $\beta 1$ leading to a decreased iNOS expression and reduced NO production [51]. The lower NO production decreases host cell microbicidal function and thus enhances parasite survival. We have recently shown that the mechanism of inhibition of NO production differs in distinct macrophage cell lines: iNOS is degraded in peritoneal macrophage-like lineage but remains expressed in RAW 264.7 lineage [52]. Santos et al. [53] isolated two subpopulations of $T$. gondii: the $\mathrm{PS}^{\mathrm{POS}}$ subpopulation exposes PS in the outer plasma membrane layer and performs apoptotic mimicry, whereas the PS ${ }^{\mathrm{NEG}}$ subpopulation display no such feature. Analysis of vacuoles formed after host cell invasion by these subpopulations reveals that $\mathrm{PS}^{\mathrm{POS}} T$. gondii are located in narrow vacuoles, indicating active penetration (Fig. 1d). In contrast, PS ${ }^{\text {NEG }}$ subpopulation of $T$. gondii dwells in large vacuoles, indicative of phagocytosis [54]. The PS ${ }^{\mathrm{POS}}$ subpopulation of $T$. gondii is the only one capable of actively penetrating non-phagocytic host cells and inhibiting NO production following activated macrophage infection (Fig. 1d). However, in in vivo infection with a mixture of both PS subpopulations promotes longer survival in mice than infection with isolated subpopulations. Infection with $\mathrm{PS}^{\mathrm{POS}}$ T. gondii triggers high parasite burden identified in animal tissue samples. In contrast, $\mathrm{PS}^{\mathrm{NEG}} T$. gondii induce an exacerbated inflammatory process. In both cases, the viability of mice is compromised [53].

\section{Non-classical apoptotic mimicry \\ Definition}

Death of host cells, either by direct effects of the infective agent or as a consequence of inflammatory cell activation are possible features of a cycle of infection [5558]. The accumulation of apoptotic cells and apoptotic bodies defines the outcome of the inflammatory and immune responses, contributing to the development of a tolerogenic environment [59-62]. In this case, parasites, viruses and possible other pathogens can coopt PS exposed by host dying cells as a strategy to create an 
environment that allows the infection to establish and to disseminate with effects on the disease severity and maintenance [55-58]. Therefore, in the last part of this review, we will discuss the consequences of PS exposing by host-derived cells for parasitic infections, the so called non-classical apoptotic mimicry [12].

\section{Plasmodium spp.}

Plasmodium is a genus of the apicomplexan phylum with more than 100 species that infect reptiles, birds and mammals [63] and has species of the Anopheles mosquitoes as vectors [64]. Humans are infected by 5 species of Plasmodium parasites ( $P$. falciparum, $P$. vivax, $P$. malariae, $P$. ovale and P. knowlesi) that cause a disease known as malaria. This is a world-spread disease, with severe complications and significant morbidity and mortality and with no available vaccine. The cycle of these parasites is complex, with an exoerythrocytic and an erythrocytic phase. The erythrocytic phase involves the infection of erythrocytes (red blood cells - RBC) by the merozoite stage, that differentiate into ring stage, followed by the trophozoite stage, shizogony and the release of new merozoites with the rupture of RBC [65]. The erythrocytic phase of the cycle consumes RBC causing anemia, which is one of the clinical manifestations of malaria. Infection of RBC by Plasmodium spp. causes a considerable stress in these host cells interfering with their normal life span.

Normal RBCs age in the circulation and end up being removed and degraded from the circulation and degraded by spleen macrophages [66]. Aged RBCs exposes PS as one of the main "eat me" signal [67]. RBCs can also suffer life-threatening damage during its life course, leading to programmed cell death known as eryptosis. This type of cell death may be caused by different cellular stress that also induces the exposure of PS and consequent phagocytosis by spleen macrophages [68]. In addition, it has been reported that Plasmodium spp. infected RBCs (iRBCs) suffer great stress and expose PS. Treatment of mice with compounds that induce eryptosis, in different models of rodent experimental malaria, results in higher PS exposure of iRBCs and lower parasitemia This indicates that induced eryptosis may be an interesting strategy to treat malaria, although, the direct effect of the compound on intracellular RBC parasites cannot be ruled out [69] Nevertheless, it is not clear how PS exposure by iRBC affects the parasite or the host [69]. Interestingly, exposure of PS by Plasmodium-iRBCs may help parasite clearance from blood by spleen macrophages [70]. Alternatively, PS exposed by iRBC may turn these cells into "Trojan horses", since PS exposure by iRBC induces uptake by macrophages, and at the same time may disarm the microbicidal capacity of these host cells due to the induction of anti-inflammatory responses [71]. Macrophage deactivation may lead to parasite persistence (Fig. 1e), which corroborates with latent merozoites forms found in the spleen of infected mice [72] and in mice dendritic cells [73].

PS is exposed by $P$. falciparum-iRBC in in vitro cultures $[74,75]$ and may be related to cytoadherence to vascular endothelium [76]. The role of PfEMP1 ( $P$. falciparum erythrocyte membrane protein 1 ) on cytoadherence by $P$. falciparum-iRBC has been demonstrated [77], but cytoadherence of iRBC involves distinct cell surface receptors [77], suggesting that PS exposure by iRBCs may also be involved. Cytoadherence, which avoids parasite removal from circulation is part of the physiopathology of malarial infection and eventually contributes to host death (Fig. 1e). PS exposure of iRBCs has been demonstrated in humans with $P$. falciparum infection [78] and in mice infected with $P$. yoelii [79] and $P$. berghei [80]. Although PS exposure has not been demonstrated in $P$. vivax-iRBC it is possible that this mechanism plays a role in human infections by this parasite [76].. Cytoadherence, which avoids parasite removal from circulation is part of the physiopathology of malarial infection and eventually contributes to host death. Furthermore, it has been demonstrated that febrile temperatures induce higher PS exposure in $P$. falciparum-iRBCs suggesting a correlation between severity and PS exposure on iRBCs in this disease [81]. On the other hand, PS exposure by iRBC may increase their phagocytosis by spleen macrophages (Fig. 1e), removing parasites from the circulation, but also causing anemia $[82,83]$. In addition, it has also been demonstrated that patients with uncomplicated $P$. falciparum and $P$. vivax malaria of display high levels of anti- phospholipid antibodies including anti-PS which may favor iRBC opsonization and parasite clearance [84]. Furthermore, it has been recently demonstrated that malaria patients infected with $P$. vivax, $P$. falciparum, $P$. knowlesi and $P$. malariae have higher IgM and IgG anti-PS antibody levels, when compared with healthy controls. The levels of anti-PS antibodies correlate with severity of patient's anemia [85]. This is especially true in patients bearing $P$. vivax infections. These facts reinforce the evidences that PS exposed in RBC of infected patients have important, implications in the pathogenesis of malarial infections. The clearance by macrophages of antibody opsonized PS exposed on iRBC exposing PS would involve FC receptors, avoiding the anti-inflammatory response caused by PS [71], which would be advantageous to the host. Finally, the treatment of mice, in different models of rodent experimental malaria, with compounds that induce eryptosis, results in higher PS exposure of iRBCs and lower parasitemia, indicating that induced eryptosis may be an interesting strategy to treat malaria, although, the direct effect of the compound on intracellular $\mathrm{RBC}$ 
parasites cannot be ruled out [69]. In summary, Plasmodium spp. infection of RBC enhances PS exposure, but the physiological role of this exposure remains to be elucidated by further in vivo studies.

\section{Entamoeba histolytica}

Amebiasis is a human disease caused by protozoan parasites of the genus Entamoeba. Some species can be found as commensal organisms in the intestinal tract. However, when they develop an invasive phenotype they can penetrate the tissues causing dysentery, colitis and liver abscesses $[86,87]$. Invasion of host tissues and disease promotion is correlated with the ability of the parasite to kill and engulf host cells. Actually, Entamoeba histolytica, the main pathogenic species, is able to induce cell death in neutrophils, epithelial cells, lymphocytes and hepatocytes, both in in vitro and in vivo conditions [88-90]. Trophozoites of E. histolytica are able to trigger a NADPH-dependent production of reactive oxygen species (ROS) in host cells, which induces the ERK1/2 and caspase 3-dependent apoptotic death of the host cell [90]. The exact mechanism by which these parasites are able to induce the apoptotic death of host cells is still unknown. Cell killing is dependent on contact mediated by lectins expressed by the parasite, interacting with $\mathrm{N}$ acetylgalactosamine containing proteoglycans expressed by host cells [88]. Liver abscesses and hepatic failure caused by E. histolytica infections can be prevented by treating infected mice with the pan-caspase inhibitor zVAD-fmk, indicating that apoptosis of host cells plays a role in pathogenesis and disease severity [91, 92]. In addition to inducing apoptotic death of host cells, virulence of E. histolytica is dependent on the ability of these parasites to engulf host cells. This process is used to identify pathogenic ameba in the gut, since it is possible to observe engulfed host cells inside the parasites in cytological analysis of gut content [88, 90, 93]. PATMK, a transmembrane kinase protein has been identified as a receptor at the surface of trophozoites that participates in the engulfment of apoptotic cells [91]. The main ligand recognized by trophozoites of E. histolytica is PS. The ability of these parasites to recognize and engulf erythrocyte and lymphocytes is correlated with PS exposure by the host cells $[89,94]$. Annexin $\mathrm{V}$ is able to inhibit ameba erythrophagocytosis up to 70\% [93]. Transfer of PS to viable lymphocytes turns these cells targets for trophozoite phagocytosis, in a specific manner since transfer of phosphatidylethanolamine or phosphatic acid are unable to induce lymphocyte engulfment [88]. The stimulation of phagocytic of E. histolytica by PS has been already demonstrated in studies with liposomes derived from erythrocyte membranes. It was observed that liposomes possessing negatively charged phospholipids induce actin polymerization and trophozoite engulfment of targets [88]. In addition, E. histolytica express a calciumdependent receptor named EhCaBP3 (E. histolytica calcium binding protein 3 ) that binds directly to PS and modulates cytoskeleton activity, mediating the phagocytosis of cellular corpses [95]. The exact consequence of the PS-dependent phagocytosis of host cells by E. histolytica trophozoites need to be further determined. However it has been clearly shown that highly pathogenic strains capable of inducing severe amebiasis are the ones adapted to induce apoptotic host cell death, recognize the "eat-me" PS-dependent signal and engulf the dead corpses [96, 97]. It is possible to hypothesize that these events may contribute to parasite nutrition, regulation of inflammation and disruption of cell barriers that prevent parasite invasion.

\section{Trypanosoma cruzi}

In addition to the already discussed role for PS exposed by trypomastigotes of $T$. cruzi, these parasites also make use of PS-derived signals from host cells. During T. cruzi experimental infection, lymphocytes show a dramatic increase in apoptotic cell death, upon activation with mitogens such as concanavalin A or anti-TCR $\alpha \beta$ agonist antibodies. This mechanism seems to be due to $\mathrm{T}$ cell exhaustion caused by chronic $\mathrm{T}$ cell stimulation triggered by chronic infection [98]. The interaction between apoptotic lymphocytes and T. cruzi infected macrophages increase the growth of the parasite in a TGF- $\beta 1$, prostaglandin and polyamine dependent way. In addition, transfer of apoptotic lymphocytes to infected mice increases parasitemia and this effect can be abolished by treatment with cyclooxygenase inhibitors, suggesting an important role of prostaglandins to increase infection [99]. These seminal results indicate that infection could increase apoptosis of critical immune cells and deactivate the immune system on behalf of the parasite, clearly demonstrating how a non-classical apoptotic mimicry operates.

\section{Leishmania spp.}

Besides the fact that both, promastigotes [44, 45] and amastigotes [5, 35], of Leishmania are able to employ classical apoptotic mimicry to establish infection, these parasites can also hijack host sources of PS, leading to persistence and dissemination, in a modified version of non-classical apoptotic mimicry. In natural and experimental infection, the earlier cells arriving at the infection site are neutrophils [100]. These cells are attracted by both inflammatory and phlebotomine salivary signals [101]. These cells can harbor Leishmania parasites, but they are not efficient as Leishmania- host cells. Intracellular differentiation and proliferation of amastigotes generally is not efficient, and tissue-infiltrating neutrophils do not survive long enough to maintain infection [102, 103]. However, the ability of promastigotes to infect and survive inside 
Table 1 Protozoan parasites in which apoptotic mimicry was described as important for disease establishment and development

\begin{tabular}{|c|c|c|c|c|c|}
\hline & \multicolumn{5}{|l|}{ Protozoan parasites } \\
\hline & Leishmania spp & Plasmodium spp & Toxoplasma gondii & Trypanosoma cruzi & Entamoeba histolytica \\
\hline Classical apoptotic mimicry & $\begin{array}{l}\text { PS exposure on } \\
\text { amastigotes and } \\
\text { promastigotes } \\
{[5,37,44,45]}\end{array}$ & - & $\begin{array}{l}\text { PS exposure on } \\
\text { tachyzoites }[51,53]\end{array}$ & $\begin{array}{l}\text { PS exposure on } \\
\text { trypomastigotes [49] }\end{array}$ & - \\
\hline Non-classical apoptotic mimicry & $\begin{array}{l}\text { PS-exposing } \\
\text { neutrophils acting } \\
\text { as Trojan horses } \\
{[105,106]}\end{array}$ & $\begin{array}{l}\text { PS exposure } \\
\text { on infected } \\
\text { RBC leading } \\
\text { to disease } \\
\text { development } \\
{[75,76,84]}\end{array}$ & - & $\begin{array}{l}\text { Apoptotic T cells } \\
\text { modulating host } \\
\text { macrophages [99] }\end{array}$ & $\begin{array}{l}\text { Phagocytosis of } \\
\text { PS-exposing apoptotic } \\
\text { host cells [89-91, 93-97] }\end{array}$ \\
\hline
\end{tabular}

neutrophils permits these parasites to escape host innate protective mechanisms such as complement factors and antimicrobial enzymes [103]. Furthermore, infected neutrophils produce chemokines such as MIP1 $\beta$, which are involved in macrophage attraction [104], the preferential host cells. Shortly after being infected, neutrophils suffer apoptotic death, which in some cases can be regulated by the parasite. The conclusion when different mouse models are studied can vary. In different reports it was observed that the parasite could induce or postpone the death of the neutrophil $[105,106]$. However, in both cases, it is clear that infected neutrophils that undergoes apoptosis act as vessels to deliver parasites to macrophages, optimizing macrophage infection [106]. This is due to the high competence of macrophages to recognize and engulf apoptotic cells and to the decrease in macrophage inflammatory activity [71]. In this scenario, PS exposure by apoptotic neutrophils plays an important role in leishmanial infection, since PS is the main ligand to promote both engulfment and regulation of inflammation. Actually, human neutrophils infected with $L$. major parasites are engulfed by macrophages when they are annexin Vpositive and therefore are exposing PS at their surface [106]. In this case, PS-exposing neutrophils act as Trojan horses, maintaining viable parasite and transferring them to macrophages [105].

\section{Conclusions}

Albeit apoptotic markers followed or not by apoptotic death, have been observed in unicellular organisms of several different groups of eukaryotes, the present review focuses exclusively on the role of PS exposure and recognition on the natural history of infection by unicellular parasites. The consequences of PS recognition in such events, independently of the origin of the cell exposing the ligand, includes induction of phagocytosis by host cells, infected cell clearance and adherence, induction of anti-PS antibodies as well as inhibition of the host inflammatory response. In the present review, we consider classical apoptotic mimicry when PS is exposed by the parasite itself and non-classical apoptotic mimicry when host cells expose the ligand in the context of the infective process. Table 1 displays both situations. It is important to consider that the cell and molecular mechanisms involved in non-classical apoptotic mimicry are in general better understood than those that are responsible for the classical form of apoptotic mimicry. This is certainly true for the biochemical machinery involved in PS exposure by multicellular host organisms when compared to the mechanism involved in PS exposure by unicellular organisms, in spite of some evidences already obtained for Leishmania spp. [39]. This is also the case regarding the molecular structure and the biosynthesis of phospholipids, including PS. As a matter of fact some controversy still remains regarding the presence and distribution of PS among the several differentiation forms of Leishmania spp. [107, 108].

It is clear that PS recognition is an important feature of host/pathogen interaction, not restricted to pathogenic protozoa, but also involved in the natural history of several important viral diseases.

\section{Abbreviations}

iNOS: Inducible nitric oxide synthase; iRBC: Infected red blood cell; KO: Knock out; MCP: Macrophage chemotactic protein; MIP1ß: Macrophage inflammatory protein; NADPH: Nicotinamide adenine dinucleotide phosphate; NO: Nitric oxide; PfEMP1: P. falciparum erythrocyte membrane protein 1; PS: Phosphatidylserine; ROS: Reactive oxygen species; TGF$\beta 1$ : Transforming growth fator $\beta 1$ ERKextracelular signal-regulated kinase

\section{Acknowledgements}

Not applicable.

\section{Authors' contributions}

$J L M W, R A D$ and MAB wrote the manuscript. All authors read and approved the final manuscript.

\section{Authors' information}

$M A B$ is a full professor at the Universidade Federal do Rio de Janeiro, Brazil. He was the leading researcher that firstly described the apoptotic mimicry and its consequences during parasite infections. RAD is an associate professor at the Universidade Estadual Norte Fluminense Darcy Ribeiro, Brazil. He described the role of phosphatidylserine (PS) exposure in experimental models of toxoplasmosis and Chagas disease. JLMW is an associate professor at the Universidade Federal do Rio de Janeiro, Brazil. He is responsible for the demonstration that PS is exposed by intracellular parasites as a counteractive response against host cell immune activation. 


\section{Funding}

No funding was received.

\section{Availability of data and materials Not applicable.}

\section{Ethics approval and consent to participate}

Not applicable.

\section{Consent for publication}

Not applicable.

\section{Competing interests}

The authors declare that they have no competing interests.

\section{Author details}

'Laboratório de Imunoparasitologia, Campus UFRJ Macaé, Universidade Federal do Rio de Janeiro, Rio de Janeiro, RJ, Brazil. 'Laboratório de Biologia Celular e Tecidual, Centro de Biociências e Biotecnologia, Universidade Estadual Norte-Fluminense, Campos dos Goytacazes, RJ, Brazil. ${ }^{3}$ Instituto de Biofísica Carlos Chagas Filho, Universidade Federal do Rio de Janeiro, Rio de Janeiro, RJ, Brazil.

\section{Received: 30 August 2019 Accepted: 11 November 2019}

\section{Published online: 15 January 2020}

\section{References}

1. DosReis GA, Barcinski MA. Apoptosis and parasitism: from the parasite to the host immune response. Adv Parasitol. 2001;49:133-61.

2. Bruchhaus I, Roeder T, Rennenberg A, Heussler VT. Protozoan parasites: programmed cell death as a mechanism of parasitism. Trends Parasitol. 2007;23:376-83.

3. Kaczanowski S, Sajid M, Reece SE. Evolution of apoptosis-like programmed cell death in unicellular protozoan parasites. Parasit Vectors. 2011:4:44.

4. Luder CG, Gross U, Lopes MF. Intracellular protozoan parasites and apoptosis: diverse strategies to modulate parasite-host interactions. Trends Parasitol. 2001:17:480-6.

5. de Freitas Balanco JM, Moreira ME, Bonomo A, Bozza PT, Amarante-Mendes G, Pirmez C, Barcinski MA. Apoptotic mimicry by an obligate intracellular parasite downregulates macrophage microbicidal activity. Curr Biol. 2001;11: 1870-3.

6. Fadok VA, Voelker DR, Campbell PA, Cohen JJ, Bratton DL, Henson PM Exposure of phosphatidylserine on the surface of apoptotic lymphocytes triggers specific recognition and removal by macrophages. J Immunol. 1992;148:2207-16

7. Fadok VA, de Cathelineau A, Daleke DL, Henson PM, Bratton DL. Loss of phospholipid asymmetry and surface exposure of phosphatidylserine is required for phagocytosis of apoptotic cells by macrophages and fibroblasts. J Biol Chem. 2001;276:1071-7.

8. Segawa K, Kurata S, Yanagihashi Y, Brummelkamp TR, Matsuda F, Nagata S. Caspase-mediated cleavage of phospholipid flippase for apoptotic phosphatidylserine exposure. Science. 2014:344:1164-8.

9. Monks J, Smith-Steinhart C, Kruk ER, Fadok VA, Henson PM. Epithelial cells remove apoptotic epithelial cells during post-lactation involution of the mouse mammary gland. Biol Reprod. 2008;78:586-94.

10. Erwig LP, Henson PM. Clearance of apoptotic cells by phagocytes. Cell Death Differ. 2008;15:243-50.

11. Birge RB, Boeltz S, Kumar S, Carlson J, Wanderley J, Calianese D, Barcinski M, Brekken RA, Huang $X$, Hutchins JT, et al. Phosphatidylserine is a global immunosuppressive signal in efferocytosis, infectious disease, and cancer. Cell Death Differ. 2016:23:962-78.

12. Amara A, Mercer J. Viral apoptotic mimicry. Nat Rev Microbiol. 2015;13:461-9.

13. Park M, Kang KW. Phosphatidylserine receptor-targeting therapies for the treatment of cancer. Arch Pharm Res. 2019:42:617-28.

14. Moller-Tank S, Maury W. Phosphatidylserine receptors: enhancers of enveloped virus entry and infection. Virology. 2014:468-470:565-80

15. Nanbo A, Kawaoka Y. Molecular mechanism of externalization of Phosphatidylserine on the surface of Ebola virus particles. DNA Cell Biol. 2019;38:115-20.

16. Vanlandschoot $P$, Leroux-Roels $G$. Viral apoptotic mimicry: an immune evasion strategy developed by the hepatitis B virus? Trends Immunol. 2003;24:144-7.
17. Lima LG, Chammas R, Monteiro RQ, Moreira ME, Barcinski MA. Tumorderived microvesicles modulate the establishment of metastatic melanoma in a phosphatidylserine-dependent manner. Cancer Lett. 2009;283:168-75.

18. Sharma B, Kanwar SS. Phosphatidylserine: a cancer cell targeting biomarker. Semin Cancer Biol. 2018:52:17-25.

19. DeRose P, Thorpe PE, Gerber DE. Development of bavituximab, a vascular targeting agent with immune-modulating properties, for lung cancer treatment. Immunotherapy. 2011;3:933-44.

20. Fischer K, Voelkl S, Berger J, Andreesen R, Pomorski T, Mackensen A. Antigen recognition induces phosphatidylserine exposure on the cell surface of human CD8+ T cells. Blood. 2006;108:4094-101.

21. Tsuchiya M, Hara Y, Okuda M, Itoh K, Nishioka R, Shiomi A, Nagao K, Mori M, Mori Y, Ikenouchi J, et al. Cell surface flip-flop of phosphatidylserine is critical for PIEZO1-mediated myotube formation. Nat Commun. 2018;9:2049.

22. van den Eijnde $S M$, van den Hoff MJ, Reutelingsperger $C P$, van Heerde $W L$, Henfling ME, Vermeij-Keers C, Schutte B, Borgers M, Ramaekers FC. Transient expression of phosphatidylserine at cell-cell contact areas is required for myotube formation. J Cell Sci. 2001;114:3631-42

23. van Kruchten R, Mattheij NJ, Saunders C, Feijge MA, Swieringa F, Wolfs JL, Collins PW, Heemskerk JW, Bevers EM. Both TMEM16F-dependent and TMEM16F-independent pathways contribute to phosphatidylserine exposure in platelet apoptosis and platelet activation. Blood. 2013;121:1850-7.

24. Rysavy NM, Shimoda LM, Dixon AM, Speck M, Stokes AJ, Turner $H_{\text {, }}$ Umemoto EY. Beyond apoptosis: the mechanism and function of phosphatidylserine asymmetry in the membrane of activating mast cells. Bioarchitecture. 2014:4:127-37.

25. Martin S, Pombo I, Poncet P, David B, Arock M, Blank U. Immunologic stimulation of mast cells leads to the reversible exposure of phosphatidylserine in the absence of apoptosis. Int Arch Allergy Immunol. 2000:123:249-58.

26. Martin SJ, Reutelingsperger CP, McGahon AJ, Rader JA, van Schie RC, LaFace DM, Green DR. Early redistribution of plasma membrane phosphatidylserine is a general feature of apoptosis regardless of the initiating stimulus: inhibition by overexpression of Bcl-2 and Abl. J Exp Med. 1995;182:1545-56.

27. Van den Eijnde SM, Boshart L, Reutelingsperger CP, De Zeeuw Cl, VermeijKeers C. Phosphatidylserine plasma membrane asymmetry in vivo: a pancellular phenomenon which alters during apoptosis. Cell Death Differ. 1997:4:311-6.

28. James SL. Role of nitric oxide in parasitic infections. Microbiol Rev. 1995;59:533-47.

29. Leishmaniasis. https://www.who.int/leishmaniasis/en/. Accessed 11 Nov 2019.

30. Bates PA. Revising Leishmania's life cycle. Nat Microbiol. 2018;3:529-30.

31. Sacks D, Noben-Trauth N. The immunology of susceptibility and resistance to Leishmania major in mice. Nat Rev Immunol. 2002;2:845-58.

32. Moreira ME, Del Portillo HA, Milder RV, Balanco JM, Barcinski MA. Heat shock induction of apoptosis in promastigotes of the unicellular organism Leishmania (Leishmania) amazonensis. J Cell Physiol. 1996;167:305-13.

33. Berman JD, Neva FA. Effect of temperature on multiplication of Leishmania amastigotes within human monocyte-derived macrophages in vitro. Am J Trop Med Hyg. 1981:30:318-21.

34. Mukkada AJ, Meade JC, Glaser TA, Bonventre PF. Enhanced metabolism of Leishmania donovani amastigotes at acid pH: an adaptation for intracellular growth. Science. 1985;229:1099-101.

35. Wanderley JL, Moreira ME, Benjamin A, Bonomo AC, Barcinski MA. Mimicry of apoptotic cells by exposing phosphatidylserine participates in the establishment of amastigotes of Leishmania (L) amazonensis in mammalian hosts. J Immunol. 2006;176:1834-9.

36. Wanderley JLM, Deolindo P, Carlsen E, Portugal AB, DaMatta RA, Barcinski MA, Soong L. CD4(+) T cell-dependent macrophage activation modulates sustained PS exposure on intracellular Amastigotes of Leishmania amazonensis. Front Cell Infect Microbiol. 2019;9:105

37. Wanderley JLM, Thorpe PE, Barcinski MA, Soong L. Phosphatidylserine exposure on the surface of Leishmania amazonensis amastigotes modulates in vivo infection and dendritic cell function. Parasite Immunol. 2013;35:109-19.

38. Louis JA, Conceicao-Silva F, Himmelrich H, Tacchini-Cottier F, Launois P. Anti-leishmania effector functions of CD4+ Th1 cells and early events instructing Th2 cell development and susceptibility to Leishmania major in BALB/c mice. Adv Exp Med Biol. 1998;452:53-60

39. Campos-Salinas J, Leon-Guerrero D, Gonzalez-Rey E, Delgado M, Castanys S, Perez-Victoria JM, Gamarro F. LABCG2, a new ABC transporter implicated in phosphatidylserine exposure, is involved in the infectivity and pathogenicity of Leishmania. PLoS Negl Trop Dis. 2013;7:e2179. 
40. Dolai S, Pal S, Yadav RK, Adak S. Endoplasmic reticulum stress-induced apoptosis in Leishmania through Ca2+-dependent and caspaseindependent mechanism. J Biol Chem. 2011;286:13638-46.

41. Garcia FP, Henrique da Silva Rodriques J, din ZU, Rodrigues-Filho E, Ueda-Nakamura T, Auzely-Velty R, Nakamura CV. A3K2A3-induced apoptotic cell death of Leishmania amazonensis occurs through caspase- and ATP-dependent mitochondrial dysfunction. Apoptosis. 2017;22:57-71.

42. Getachew F, Gedamu L. Leishmania donovani mitochondrial iron superoxide dismutase a is released into the cytosol during miltefosine induced programmed cell death. Mol Biochem Parasitol. 2012;183:42-51.

43. Crauwels P, Bohn R, Thomas M, Gottwalt S, Jackel F, Kramer S, Banke E, Tenzer S, Walther P, Bastian M, van Zandbergen G. Apoptotic-like Leishmania exploit the host's autophagy machinery to reduce T-cellmediated parasite elimination. Autophagy. 2015;11:285-97.

44. van Zandbergen G, Bollinger A, Wenzel A, Kamhawi S, Voll R, Klinger M, Muller A, Holscher C, Herrmann M, Sacks D, et al. Leishmania disease development depends on the presence of apoptotic promastigotes in the virulent inoculum. Proc Natl Acad Sci U S A. 2006;103:13837-42.

45. Wanderley $J$, Pinto da Silva LH, Deolindo P, Soong L, Borges VM, Prates DB, de Souza AP, Barral A, Balanco JM, do Nascimento MT, et al. Cooperation between apoptotic and viable metacyclics enhances the pathogenesis of Leishmaniasis. PLoS One. 2009;4:e5733.

46. Inbar E, Hughitt VK, Dillon LA, Ghosh K, El-Sayed NM, Sacks DL. TheTranscriptome of Leishmania major developmental stages in their natural sand Fly vector. MBio. 2017;8:e00029-17.

47. Lidani KCF, Andrade FA, Bavia L, Damasceno FS, Beltrame MH, MessiasReason IJ, Sandri TL. Chagas disease: from discovery to a worldwide health problem. Front Public Health. 2019;7:166.

48. de Souza W, de Carvalho TM, Barrias ES. Review on Trypanosoma cruzi: host cell interaction. Int J Cell Biol. 2010;2010:295394.

49. Damatta RA, Seabra SH, Deolindo P, Arnholdt AC, Manhaes L, Goldenberg S, de Souza W. Trypanosoma cruzi exposes phosphatidylserine as an evasion mechanism. FEMS Microbiol Lett. 2007;266:29-33.

50. Cenci-Goga BT, Rossitto PV, Sechi P, McCrindle CM, Cullor JS. Toxoplasma in animals, food, and humans: an old parasite of new concern. Foodborne Pathog Dis. 2011:8:751-62.

51. Seabra SH, de Souza W, Damatta RA. Toxoplasma gondii exposes phosphatidylserine inducing a TGF-beta1 autocrine effect orchestrating macrophage evasion. Biochem Biophys Res Commun. 2004;324:744-52.

52. Cabral GRA, Wang ZT, Sibley LD, DaMatta RA. Inhibition of nitric oxide production in activated macrophages caused by toxoplasma gondii infection occurs by distinct mechanisms in different mouse macrophage cell lines. Front Microbiol. 2018:9:1936.

53. Santos TA, Portes Jde A, Damasceno-Sa JC, Caldas LA, Souza W, Damatta RA, Seabra SH. Phosphatidylserine exposure by toxoplasma gondii is fundamental to balance the immune response granting survival of the parasite and of the host. PLoS One. 2011;6:e27867.

54. Morisaki JH, Heuser JE, Sibley LD. Invasion of toxoplasma gondii occurs by active penetration of the host cell. J Cell Sci. 1995;108(Pt 6):2457-64.

55. Mammari N, Halabi MA, Yaacoub S, Chlala H, Darde ML, Courtioux B. Toxoplasma gondii modulates the host cell responses: an overview of apoptosis pathways. Biomed Res Int. 2019:2019:6152489.

56. Alberdi P, Espinosa PJ, Cabezas-Cruz A, de la Fuente J. Anaplasma phagocytophilum manipulates host cell apoptosis by different mechanisms to establish infection. Vet Sci. 2016;3:15.

57. Rodrigues V, Cordeiro-da-Silva A, Laforge M, Ouaissi A, Silvestre R, Estaquier J. Modulation of mammalian apoptotic pathways by intracellular protozoan parasites. Cell Microbiol. 2012;14:325-33.

58. Galluzzi L, Brenner C, Morselli E, Touat Z, Kroemer G. Viral control of mitochondrial apoptosis. PLoS Pathog. 2008;4:e1000018.

59. Albert ML. Death-defying immunity: do apoptotic cells influence antigen processing and presentation? Nat Rev Immunol. 2004;4:223-31.

60. Albert ML, Pearce SF, Francisco LM, Sauter B, Roy P, Silverstein RL, Bhardwaj N. Immature dendritic cells phagocytose apoptotic cells via alphavbeta5 and CD36, and cross-present antigens to cytotoxic T lymphocytes. J Exp Med. 1998;188:1359-68.

61. Blachere NE, Darnell RB, Albert ML. Apoptotic cells deliver processed antigen to dendritic cells for cross-presentation. PLoS Biol. 2005;3:e185.

62. Sauter B, Albert ML, Francisco L, Larsson M, Somersan S, Bhardwaj N. Consequences of cell death: exposure to necrotic tumor cells, but not primary tissue cells or apoptotic cells, induces the maturation of immunostimulatory dendritic cells. J Exp Med. 2000;191:423-34.

63. De Niz M, Heussler VT. Rodent malaria models: insights into human disease and parasite biology. Curr Opin Microbiol. 2018;46:93-101.

64. Romoli O, Gendrin M. The tripartite interactions between the mosquito, its microbiota and Plasmodium. Parasit Vectors. 2018;11:200.

65. Cowman AF, Healer J, Marapana D, Marsh K. Malaria: biology and disease. Cell. 2016;167:610-24.

66. Le wis SM, Williams A, Eisenbarth SC. Structure and function of the immune system in the spleen. Sci Immunol. 2019;4:eaau6085

67. de Back DZ, Kostova EB, van Kraaij M, van den Berg TK, van Bruggen R. Of macrophages and red blood cells; a complex love story. Front Physiol. 2014;5:9.

68. Lutz HU, Bogdanova A. Mechanisms tagging senescent red blood cells for clearance in healthy humans. Front Physiol. 2013;4:387.

69. Boulet C, Doerig CD, Carvalho TG. Manipulating Eryptosis of human red blood cells: a novel antimalarial strategy? Front Cell Infect Microbiol. 2018;8:419.

70. Qadri SM, Bissinger R, Solh Z, Oldenborg PA. Eryptosis in health and disease: a paradigm shift towards understanding the (patho) physiological implications of programmed cell death of erythrocytes. Blood Rev. 2017:31:349-61.

71. Fadok VA, Bratton DL, Konowal A, Freed PW, Westcott JY, Henson PM. Macrophages that have ingested apoptotic cells in vitro inhibit proinflammatory cytokine production through autocrine/paracrine mechanisms involving TGF-beta, PGE2, and PAF. J Clin Invest. 1998;101:890-8.

72. Landau I, Chabaud AG, Mora-Silvera E, Coquelin F, Boulard Y, Renia L, Snounou G. Survival of rodent malaria merozoites in the lymphatic network: potential role in chronicity of the infection. Parasite. 1999;6:311-22.

73. Wykes MN, Kay JG, Manderson A, Liu XQ, Brown DL, Richard DJ, Wipasa J, Jiang $\mathrm{SH}$, Jones MK, Janse CJ, et al. Rodent blood-stage Plasmodium survive in dendritic cells that infect naive mice. Proc Natl Acad Sci U S A. 2011;108: 11205-10.

74. Eda S, Sherman IW. Cytoadherence of malaria-infected red blood cells involves exposure of phosphatidylserine. Cell Physiol Biochem. 2002;12:373-84.

75. Sherman IW, Prudhomme J, Tait JF. Altered membrane phospholipid asymmetry in Plasmodium falciparum-infected erythrocytes. Parasitol Today. 1997;13:242-3.

76. Totino PR, Lopes SC. Insights into the Cytoadherence phenomenon of Plasmodium vivax: the putative role of Phosphatidylserine. Front Immunol. 2017:8:1148

77. Pasternak ND, Dzikowski R. PfEMP1: an antigen that plays a key role in the pathogenicity and immune evasion of the malaria parasite Plasmodium falciparum. Int J Biochem Cell Biol. 2009;41:1463-6.

78. Butthep P, Wanram S, Pattanapanyasat K, Vattanaviboon P, Fucharoen S, Wilairat P. Cytoadherence between endothelial cells and $P$. falciparum infected and noninfected normal and thalassemic red blood cells. Cytometry B Clin Cytom. 2006;70:432-42.

79. Totino PR, Magalhaes AD, Silva LA, Banic DM, Daniel-Ribeiro CT, Ferreira-daCruz Mde F. Apoptosis of non-parasitized red blood cells in malaria: a putative mechanism involved in the pathogenesis of anaemia. Malar J. 2010;9:350.

80. Alesutan I, Bobbala D, Qadri SM, Estremera A, Foller M, Lang F. Beneficial effect of aurothiomalate on murine malaria. Malar J. 2010;9:118.

81. Pattanapanyasat K, Sratongno P, Chimma P, Chitjamnongchai S, Polsrila K, Chotivanich K. Febrile temperature but not proinflammatory cytokines promotes phosphatidylserine expression on Plasmodium falciparum malaria-infected red blood cells during parasite maturation. Cytometry A. 2010;77:515-23.

82. Foller M, Bobbala D, Koka S, Boini KM, Mahmud H, Kasinathan RS, Shumilina E, Amann K, Beranek G, Sausbier U, et al. Functional significance of the intermediate conductance Ca2+-activated $\mathrm{K}+$ channel for the short-term survival of injured erythrocytes. Pflugers Arch. 2010:460:1029-44.

83. Totino PR, Daniel-Ribeiro CT, Ferreira-da-Cruz MF. Evidencing the role of Erythrocytic apoptosis in malarial Anemia. Front Cell Infect Microbiol. 2016;6:176.

84. Facer CA, Agiostratidou G. High levels of anti-phospholipid antibodies in uncomplicated and severe Plasmodium falciparum and in P. vivax malaria. Clin Exp Immunol. 1994;95:304-9.

85. Barber BE, Grigg MJ, Piera K, Amante FH, William T, Boyle MJ, Minigo G, Dondorp AM, JS MC, Anstey NM. Anti-phosphatidylserine lgM nd IgG antibodies are higher in vivax than falciparum malaria, and associated with early anemia in both species. J Infect Dis. 2019;220:1435.

86. Betanzos A, Banuelos C, Orozco E. Host invasion by pathogenic amoebae: epithelial disruption by parasite proteins. Genes (Basel). 2019;10:618. 
87. Ghosh S, Padalia J, Moonah S. Tissue destruction caused by Entamoeba histolytica parasite: cell death, inflammation, invasion, and the gut microbiome. Curr Clin Microbiol Rep. 2019;6:51-7.

88. Huston CD, Boettner DR, Miller-Sims V, Petri WA Jr. Apoptotic killing and phagocytosis of host cells by the parasite Entamoeba histolytica. Infect Immun. 2003:71:964-72.

89. Kim KA, Lee YA, Shin MH. Calpain-dependent calpastatin cleavage regulates caspase-3 activation during apoptosis of Jurkat T cells induced by Entamoeba histolytica. Int J Parasitol. 2007;37:1209-19.

90. Sim S, Yong TS, Park SJ, Im Kl, Kong Y, Ryu JS, Min DY, Shin MH. NADPH oxidase-derived reactive oxygen species-mediated activation of ERK1/2 is required for apoptosis of human neutrophils induced by Entamoeba histolytica. J Immunol. 2005;174:4279-88.

91. Boettner DR, Huston CD, Linford AS, Buss SN, Houpt E, Sherman NE, Petri WA Jr. Entamoeba histolytica phagocytosis of human erythrocytes involves PATMK, a member of the transmembrane kinase family. PLoS Pathog. 2008;4:e8

92. Yan L, Stanley SL Jr. Blockade of caspases inhibits amebic liver abscess formation in a mouse model of disease. Infect Immun. 2001; 69:7911-4.

93. Boettner DR, Huston CD, Sullivan JA, Petri WA Jr. Entamoeba histolytica and Entamoeba dispar utilize externalized phosphatidylserine for recognition and phagocytosis of erythrocytes. Infect Immun. 2005;73: 3422-30.

94. Lee YA, Kim KA, Min A, Shin MH. Amoebic PI3K and PKC is required for Jurkat T cell death induced by Entamoeba histolytica. Korean J Parasitol. 2014;52:355-65.

95. Aslam S, Bhattacharya S, Bhattacharya A. The Calmodulin-like calcium binding protein EhCaBP3 of Entamoeba histolytica regulates phagocytosis and is involved in actin dynamics. PLoS Pathog. 2012;8:e1003055.

96. Triss D, Martinez-Palomo A, de la Torre M, de la Hoz R, Perez de Suarez E. Surface properties of Entamoeba: increased rates of human erythrocyte phagocytosis in pathogenic strains. J Exp Med. 1978;148:1137-43.

97. Orozco E, Guarneros G, Martinez-Palomo A, Sanchez T. Entamoeba histolytica. Phagocytosis as a virulence factor. J Exp Med. 1983;158:1511-21.

98. Lopes MF, da Veiga VF, Santos AR, Fonseca ME, DosReis GA. Activationinduced CD4+ T cell death by apoptosis in experimental Chagas' disease. J Immunol. 1995;154:744-52

99. Freire-de-Lima CG, Nascimento DO, Soares MB, Bozza PT, Castro-Faria-Neto HC, de Mello FG, DosReis GA, Lopes MF. Uptake of apoptotic cells drives the growth of a pathogenic trypanosome in macrophages. Nature. 2000;403: 199-203.

100. Peters NC, Egen JG, Secundino N, Debrabant A, Kimblin N, Kamhawi S, Lawyer P, Fay MP, Germain RN, Sacks D. In vivo imaging reveals an essential role for neutrophils in leishmaniasis transmitted by sand flies. Science. 2008; 321:970-4.

101. Teixeira CR, Santos CDS, Prates DB, Dos Santos RT, Araujo-Santos T, de Souza-Neto SM, Borges VM, Barral-Netto M, Brodskyn Cl. Lutzomyia longipalpis saliva drives Interleukin-17-induced neutrophil recruitment favoring Leishmania infantum infection. Front Microbiol. 2018;9:881.

102. Tak T, Tesselaar K, Pillay J, Borghans JA, Koenderman L. What's your age again? Determination of human neutrophil half-lives revisited. J Leukoc Biol. 2013;94:595-601

103. Hurrell BP, Regli IB, Tacchini-Cottier F. Different Leishmania species drive distinct neutrophil functions. Trends Parasitol. 2016;32:392-401.

104. Muller K, van Zandbergen G, Hansen B, Laufs H, Jahnke N, Solbach W, Laskay T. Chemokines, natural killer cells and granulocytes in the early course of Leishmania major infection in mice. Med Microbiol Immunol. 2001;190:73-6.

105. Laskay T, van Zandbergen G, Solbach W. Neutrophil granulocytes as host cells and transport vehicles for intracellular pathogens: apoptosis as infection-promoting factor. Immunobiology. 2008;213:183-91.

106. van Zandbergen G, Klinger M, Mueller A, Dannenberg S, Gebert A, Solbach W, Laskay T. Cutting edge: neutrophil granulocyte serves as a vector for Leishmania entry into macrophages. J Immunol. 2004;173: 6521-5.

107. Imbert L, Ramos RG, Libong D, Abreu S, Loiseau PM, Chaminade P. Identification of phospholipid species affected by miltefosine action in Leishmania donovani cultures using LC-ELSD, LC-ESI/MS, and multivariate data analysis. Anal Bioanal Chem. 2012:402:1169-82.
108. Weingartner A, Kemmer G, Muller FD, Zampieri RA, Gonzaga dos Santos M, Schiller J, Pomorski TG. Leishmania promastigotes lack phosphatidylserine but bind annexin $V$ upon permeabilization or miltefosine treatment. PLoS One. 2012;7:e42070.

\section{Publisher's Note}

Springer Nature remains neutral with regard to jurisdictional claims in published maps and institutional affiliations.

\section{Ready to submit your research? Choose BMC and benefit from:}

- fast, convenient online submission

- thorough peer review by experienced researchers in your field

- rapid publication on acceptance

- support for research data, including large and complex data types

- gold Open Access which fosters wider collaboration and increased citations

- maximum visibility for your research: over $100 \mathrm{M}$ website views per year

At BMC, research is always in progress.

Learn more biomedcentral.com/submissions 